\title{
Penerapan Teknologi Augmented Reality Untuk Pembelajaran Gerbang Logika Pada Mata Pelajaran Sistem Komputer
}

\author{
Mochammad Machlul Alamin ${ }^{1}$, Hendrawan Armanto ${ }^{2}$, Indra Maryati ${ }^{3}$ \\ ${ }^{1}$ Program Studi Teknologi Informasi, Institut Sains dan Teknologi Terpadu Surabaya, Surabaya, Indonesia \\ ${ }^{2}$ Program Studi Teknik Informatika, Institut Sains dan Teknologi Terpadu Surabaya, Surabaya, Indonesia \\ ${ }^{3}$ Program Studi Sistem Informasi Bisnis, Institut Sains dan Teknologi Terpadu Surabaya, Surabaya, Indonesia \\ Email: ${ }^{1}$ mochammadmachlul@gmail.com, ${ }^{2}$ hendrawan@ stts.edu, ${ }^{3}$ maryati@ stts.edu \\ Email Penulis Korespondensi: mochammadmachlul@gmail.com
}

\begin{abstract}
Abstrak-Gerbang Logika adalah Salah satu materi pada mata pelajaran Sistem Komputer tingkat SMK kelas X. Namun hingga saat ini media pembelajaran hanya menggunakan buku materi ajar, slide power point dan simulasi manual menggunakan papan tulis. Sementara materi tentang gerbang logika ini sangat sulit jika tidak di simulasikan secara langsung karena berhubungan langsung dengan interaksi input dan output pada masing-masing gerbang logika. Selama menggunakan media buku ajar dan simulasi manual ini siswa sulit untuk memahami materi tentang gerbang logika ini. Kelebihan dari pembelajaran yang memanfaatkan Augmented Reality ini adalah tampilan yang menarik dan menampilkan objek 3D gerbang logika beserta tombol input yang bisa digunakan untuk berinteraksi secara langsung dan outputnya juga berupa objek 3D lampu, dengan adanya teknologi Augmented Reality ini akan sangat membantu dan berguna untuk mensimulasikan gerbang logika secara langsung dan mudah difahami oleh siswa. Animasi gerbang logika 3D dibuat menggunakan aplikasi 3D Blender dan proses Augmented Reality dibuat dengan menggunakan Unity dan Library Vuforia SDK. Aplikasi pembelajaran gerbang logika ini telah diaplikasikan kepada dua kelas yaitu kelas kontrol dan kelas eksperimen. Dari hasil pengujian Pre Test dan Post Test yang telah dilakukan, untuk kelas kontrol memiliki presentase kenaikan 22,0\%, sedangkan untuk kelas eksperimen memiliki presentase kenaikan 33,4\%. Dengan demikian aplikasi pembelajaran yang memanfaatkan teknologi Augmented Reality ini dapat diterapkan sebagai media pembelajaran gerbang logika di tingkat SMK kelas X.
\end{abstract}

Kata Kunci: Gerbang Logika, Augmented Reality, Sistem Komputer, Media Pembelajaran, Android

\begin{abstract}
Logic Gate is one of the materials in the subject of Computer Systems at the level of SMK in class X. However, until now the learning media only uses textbooks, power point slides and manual simulations using blackboards. While the material about logic gates is very difficult if it is not directly simulated because it is directly related to the interaction of inputs and outputs at each logic gate. During the use of textbooks and manual simulation media students find it difficult to understand the material about this logic gate. The advantage of learning that utilizes augmented reality is an attractive display and displays 3D logic gate objects and input buttons that can be used to interact directly and the output is also in the form of 3D lamp objects, with this augmented reality technology will be very helpful and useful for simulating the gate logic is directly and easily understood by students. 3D logic gate animations are created using the 3D Blender application and the Augmented Reality process is created using the Unity and Vuforia SDK Library. This logic gate learning application has been applied to two classes, namely the control class and the experimental class. From the results of the Pre Test and Post Test that have been done, the control class has a $22.0 \%$ increase in percentage, while the experimental class has a $33.4 \%$ increase in percentage. Thus the learning application that utilizes Augmented Reality technology can be applied as a medium for learning logic gates at the vocational level of class $\mathrm{X}$.
\end{abstract}

Keywords: Logic Gate, Augmented Reality, Computer System, Learning Media, Android

\section{PENDAHULUAN}

Di era modern saat ini kehadiran teknologi membawa dampak yang sangat signifikan, peran teknologi memberikan solusi untuk mengatasi berbagai permasalahan yang ada. Salah satu teknologi terbaru yang ada saat ini adalah teknologi Augmented Reality yang bisa memunculkan objek 3D pada ponsel cerdas, sehingga cocok digunakan sebagai salah satu alternatif pada suatu metode pembelajaran yang asyik, interaktif, menarik, dan dapat meningkatkan minat belajar siswa.

Salah satu kelebihan teknologi Augmented Reality adalah dapat digunakan untuk membantu memvisualisasikan konsep abstrak untuk pengenalan dan pemahaman suatu obyek[1], Salah satu kelebihan yang diterapkan dalam proses pembelajaran yaitu untuk memperlihatkan objek atau situasi yang tidak dapat terlihat langsung oleh siswa[2]. Sayangnya masih belum banyak ditemukan pada pembelajaran gerbang logika yang menerapkan teknologi Augmented Reality ini.

Kebanyakan sumber belajar saat ini masih menggunakan buku ajar Sistem Komputer SMK kelas X[3], serta masih menggunakan power point dan menggunakan papan tulis untuk simulasi pada pembelajaran gerbang logika. Sehingga siswa cenderung tidak fokus pada pembelajaran dan lebih tidak tertarik pada pembelajaran yang manual. Melihat permasalahan tersebut diatas maka dilakukan penelitian ini dengan tujuan untuk mempermudah proses pembelajaran gerbang logika dengan memanfaatkan teknologi Augmented Reality berbasis android ini sebagai alternatif metode pembelajaran dan simulasi gerbang logika dilakukan secara langsung sehingga diharapkan mempermudah daya ingat siswa dan dapat langsung memahami simbol setiap gerbang logika beserta interaksi input dan output pada setiap gerbang logika.

Beberapa penelitian terdahulu yang relevan dengan penelitian ini antara lain seperti penelitian dari $\mathrm{R}$ Hutahaean, R.R Isnanto, K Teguh Martono "Perancangan Aplikasi Multimedia Untuk Pembelajaran Gerbang 
JURNAL MEDIA INFORMATIKA BUDIDARMA

Volume 4, Nomor 3, Juli 2020, Page 503-510

ISSN 2614-5278 (media cetak), ISSN 2548-8368 (media online)

Available Online at https://ejurnal.stmik-budidarma.ac.id/index.php/mib

DOI 10.30865/mib.v4i3.2128

Logika Menggunakan Augmented Reality"[4], Penelitian yang lain seperti penelitian dari H Setiahadi, E Setyati dan E Irawati Setiawan, "Pembelajaran Ikatan Molekul Dalam Pelajaran Kimia Menggunakan Augmented Reality"[5], Penelitian yang lain seperti penelitian dari R Mauludin, A Srimurdianti Sukamto dan H Muhardi, "Penerapan Augmented Reality Sebagai Media Pembelajaran Sistem Pencernaan Pada Manusia dalam Mata Pelajaran Biologi"'6]. Penelitian yang lain seperti penelitian dari A Pramono dan M D Setiawan, "Pemanfaatan Augmented Reality Sebagai Media Pembelajaran Pengenalan Buah-Buahan”[7].

\section{METODE PENELITIAN}

\subsection{Kerangka Penelitian}

Adapun kerangka penelitian pada penelitian ini dapat dilihat pada Gambar 1 sebagai berikut.

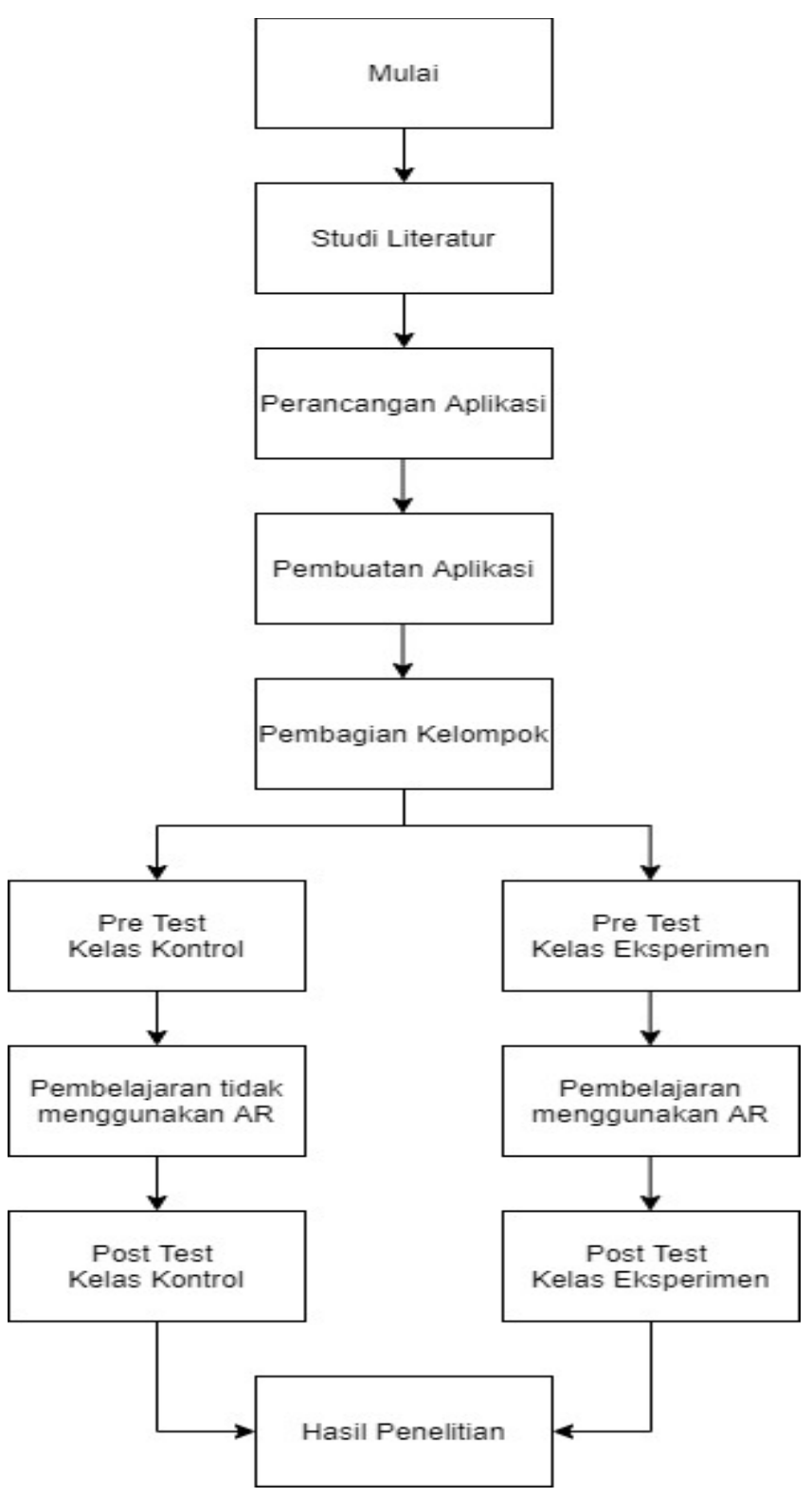

Gambar 1. Kerangka Penelitian

Penjelasan kerangka penelitian pada Gambar 1 diatas adalah sebagai berikut :

a. Studi Literatur, mencari dan mempelajari literatur dari buku, jurnal, serta penelitian sebelumnya yang berkaitan dengan penelitian ini. Salah satu buku yang menjadi literatur adalah buku ajar mata pelajaran Sistem Komputer SMK Kelas X.

b. Perancangan Aplikasi, dalam perancangan aplikasi pada penelitian ini mencakup beberapa tahapan, yaitu perancangan objek 3D, perancangan marker, perancangan tampilan aplikasi (User Interface) serta pembuatan soal Pre Test dan soal Post Test. 
c. Pembuatan Aplikasi, setelah pada tahap perancangan aplikasi telah selesai maka pada tahap selanjutnya yaitu pembuatan aplikasi yang menggunakan Software Unity $3 D$.

d. Pembagian Kelompok

Adapun yang menjadi responden dalam penelitian ini merupakan siswa SMK kelas X yang berjumlah 60 siswa yang terdiri dari dua kelas. Dari dua kelas ini akan dibagi menjadi dua kelompok yaitu kelas kontrol dan kelas eksperimen. Kelas kontrol adalah kelas yang pembelajaran gerbang logika tidak menggunakan aplikasi augmented reality, sedangkan kelas eksperimen adalah kelas yang pembelajaran gerbang logika menggunakan aplikasi Augmented Reality. Pada Tabel 1 dijelaskan profil dari responden.

Tabel 1. Profil Responden

\begin{tabular}{cccc}
\hline No & Responden & Kelompok & Jumlah Siswa \\
\hline \multirow{2}{*}{1} & Kelas X TKJ 1 & Kelas Kontrol & 30 siswa \\
& $\begin{array}{c}\text { Laki-Laki }=12 \text { siswa } \\
\text { Perempuan }=18 \text { siswa } \\
\text { Kelas X TKJ 2 } \\
\text { Laki-Laki }=11 \text { siswa } \\
2\end{array}$ & Kelas Eksperimen & 30 siswa \\
& Perempuan $=19$ siswa & & \\
\hline
\end{tabular}

e. Pre Test dan Post Test

Pre Test adalah Soal yang diujikan kepada seluruh siswa yang terdiri dari dua kelompok kelas tersebut. Soal Pre Test diujikan sebagai Latihan dan diujikan sebelum diajarkan materi gerbang logika.

Post Test adalah Soal yang diujikan kepada seluruh siswa yang terdiri dari dua kelompok kelas tersebut. Soal Post Test diujikan sebagai Latihan dan diujikan sesudah diajarkan materi gerbang logika.

Soal Pre Test dan Post Test terdiri dari 20 sampel pertanyaan. Jawaban benar diberi nilai 5, sedangkan jawaban salah diberi nilai 0 .

f. Hasil Penelitian, dari penelitian ini dapat dihasilkan berupa aplikasi yang telah dibuat ini apakah dapat membantu atau tidak membantu dalam proses pembelajaran rangkaian logika pada mata pelajaran Sistem Komputer SMK Kelas X. Dengan membandingkan hasil nilai Pre Test dan hasil Post Test siswa pada masingmasing kelompok kelas, yaitu pada kelas kontrol dan kelas eksperimen. Jika hasil kenaikan nilai lebih besar kelas eksperimen daripada kelas kontrol maka aplikasi pembelajaran gerbang logika menggunakan Augmented Reality ini dapat membantu proses pembelajaran. Jika hasil kenaikan nilai lebih besar kelas kontrol daripada kelas eksperimen maka aplikasi pembelajaran gerbang logika menggunakan augmented reality ini tidak dapat membantu proses pembelajaran.

\subsection{Blok Diagram}

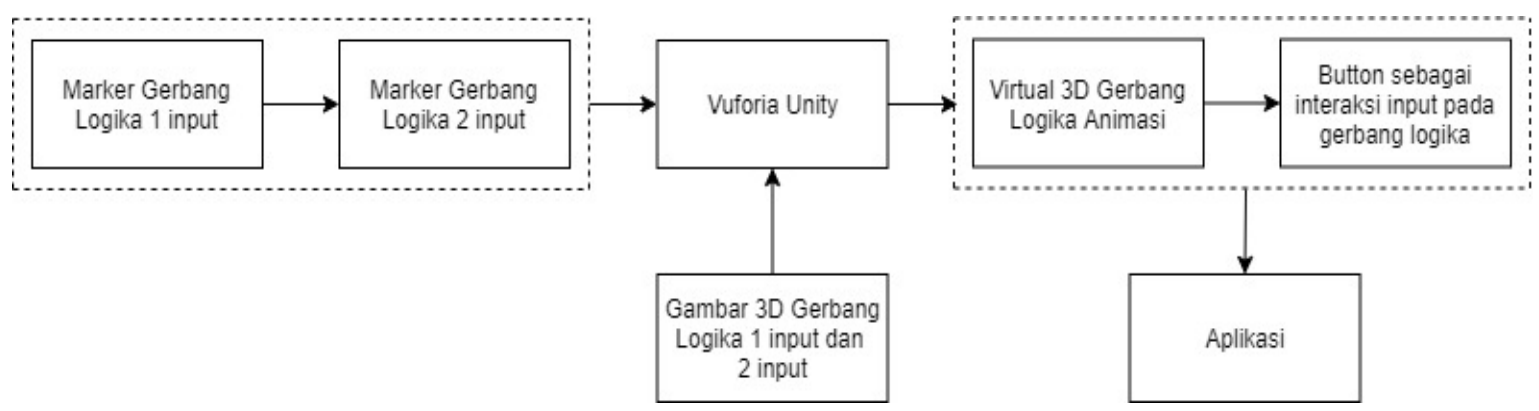

Gambar 2. Blok Diagram

Gambar 2 merupakan Blok Diagram dalam pembuatan aplikasi Augmented Reality pembelajaran gerbang logika. Pembuatan aplikasi pembelajaran ini dimulai dengan modeling $3 D$ objek. Objek dibuat sesuai dengan materi pembahasan yaitu gerbang logika 1 input yakni gerbang NOT. Gerbang logika 2 input yakni gerbang AND, OR, NAND, NOR, XOR, dan XNOR. Objek yang sudah selesai dibuat, akan diberi button seperti halnya saklar 0 dan 1 pada input masing-masing gerbang logika, sehingga sebagai interaksi input yang bisa diubah antara 0 dan 1 .

\subsection{Augmented Reality}

Augmented Reality adalah sebuah teknik yang menggabungkan benda maya dua dimensi maupun tiga dimensi ke dalam sebuah lingkup nyata.[8]. Augmented Reality adalah sebuah pendekatan untuk memvisualisasikan maya diatas citra fisik dan memanipulasi informasi maya melalui interaksi dengan objek realworld[9]. Augmented Reality (AR) adalah sebuah istilah untuk lingkungan yang menggabungkan dunia nyata dan dunia virtual yang dibuat oleh komputer sehingga batas antara keduanya menjadi sangat tipis. Sistem ini lebih dekat kepada lingkungan nyata (real). Karena itu, reality lebih diutamakan pada sistem ini (Brian, 2012)[10]. 

DOI 10.30865/mib.v4i3.2128

\subsection{Unity 3D}

Software Unity 3D merupakan Game Engine atau software yang digunakan untuk membuat Video Game. Unity $3 D$ sendiri dikembangkan oleh Unity Technologies. "Unity adalah sebuah Game Engine yang memungkinkan baik perseorangan maupun tim untuk membuat sebuah Game 3D dengan mudah dan cepat".

\subsection{Vuforia}

Vuforia merupakan library yang digunakan sebagai pendukung adanya Augmented Reality pada android. Vuforia menganalisa gambar dengan menggunakan pendeteksi marker dan menghasilkan informasi 3D dari marker yang sudah dideteksi via API (Developer Vuforia)[11].

\section{HASIL DAN PEMBAHASAN}

\subsection{Implementasi Marker}

Pada penelitian pembelajaran gerbang logika menggunakan Augmented Reality ini menggunakan marker based augmented reality sebagai penanda. Dengan menggunakan marker sebagai penanda untuk menampilkan objek 3D ke dalam kamera Augmented Reality. Marker yang telah didesain akan dimasukkan ke dalam image target database yang ada pada vuforia[12]. Marker yang digunakan dalam penelitian ini adalah marker gerbang logika dasar satu input dan gerbang logika dasar dua input seperti yang ditunjukkan pada gambar 3 dibawah. Marker ini berfungsi untuk dibaca dan kenali oleh kamera lalu dicocokkan dengan template pada ARToolkit. Setelah itu kamera akan memunculkan gambar objek 3D gerbang logika beserta tombol input berupa 0 dan 1 seperti halnya saklar pada umumnya.

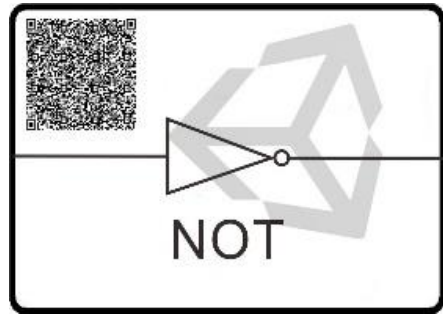

a)

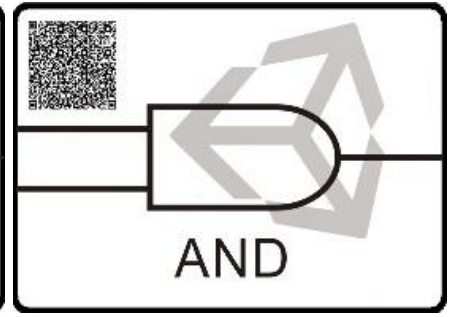

b)

Gambar 3. a). Gerbang Logika 1 input; b). Gerbang Logika 2 input

\subsection{Implementasi Objek 3D}

Pada penelitian ini proses pembuatan objek 3D menggunakan aplikasi Blender versi 2.81. Objek 3D akan muncul pada layar ketika marker yang sudah didaftarkan sudah berhasil diidentifikasi. Objek 3D akan muncul berbedabeda sesuai marker yang dikenali oleh kamera. Hasil dari pembuatan objek 3D seperti Gambar 4.

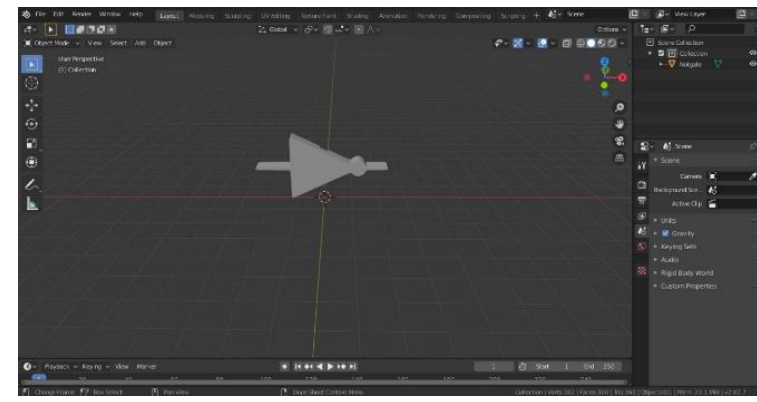

a)

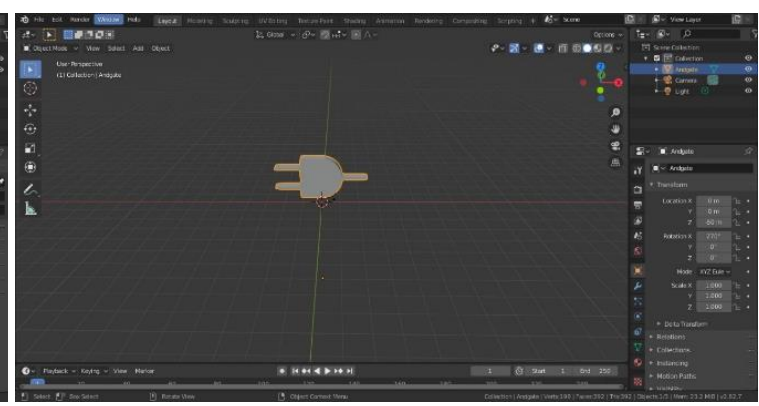

b)

Gambar 4. a). Hasil Pembuatan Objek 3D 1 input; b). Hasil Pembuatan Objek 3D 2 input

\subsection{Implementasi Aplikasi}

Berikut merupakan hasil dari tampilan aplikasi pembelajaran gerbang logika dengan Augmented Reality berbasis android yang dipasang pada perangkat smartphone pada resolusi layar 1440 x 720 pixels :

\section{A. Halaman Splashscreen}

Ketika aplikasi pembelajaran gerbang logika menggunakan Augmented Reality ini dijalankan, maka akan muncul halaman splashscreen seperti pada Gambar 5. Halaman splashscreen ini akan muncul selama 1.5 detik. 


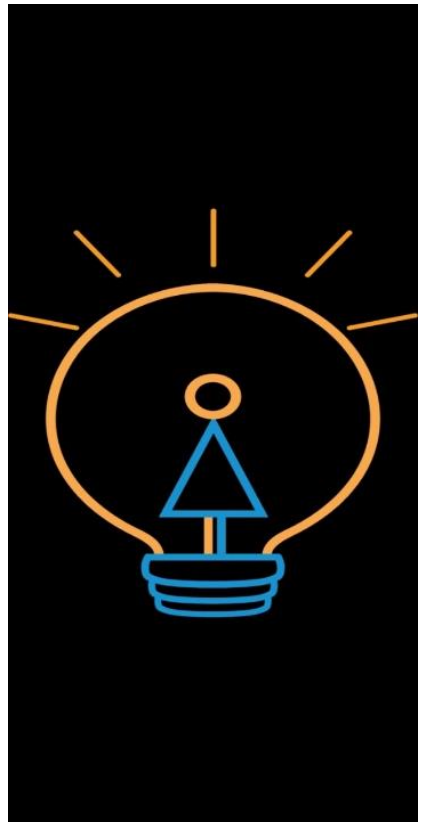

Gambar 5. Tampilan Halaman Splashscreen

\section{B. Halaman Menu Utama}

Pada halaman menu utama ini terdapat simbol aplikasi dan nama aplikasi serta tiga tombol utama yaitu Menu Mulai, Menu Tentang, dan Menu Keluar. Tampilan Halaman Menu Utama pada aplikasi pembelajaran gerbang logika menggunakan Augmented Reality seperti pada Gambar 6.

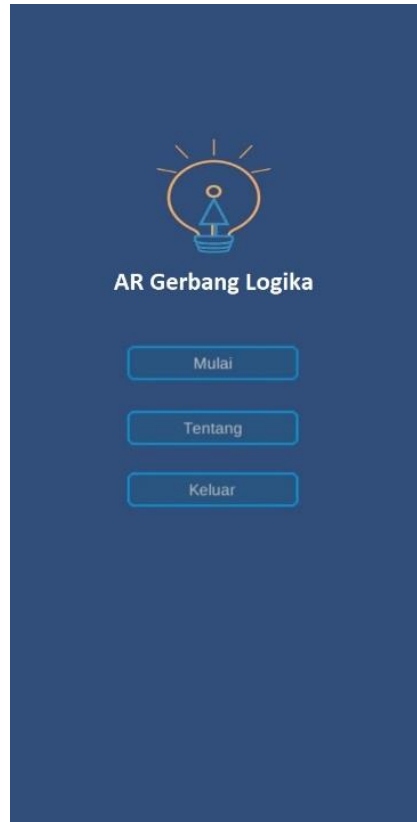

Gambar 6. Tampilan Halaman Menu Utama

\section{Halaman Mulai}

Pada saat menu mulai ditekan, maka aplikasi akan secara langsung menampilkan kamera Augmented Reality yang belum mendeteksi marker dan belum memunculkan objek 3D, Pada saat user mengarahkan kamera ke marker yang sudah terdaftar maka kamera secara langsung akan mengidentifikasi marker dan langsung menampilkan objek 3D sesuai marker yang dikenali[13]. Pada saat objek 3D muncul, secara langsung juga muncul tombol input 0 dan 1 seperti halnya saklar. Jika tombol 0 ditekan, maka akan berubah menjadi 1 begitu pula sebaliknya jika tombol 1 ditekan maka akan berubah menjadi 0 . Tombol On Off sebelah kanan berfungsi untuk keluar dari aplikasi dan tombol layar warna biru berfungsi untuk kembali ke menu utama. 


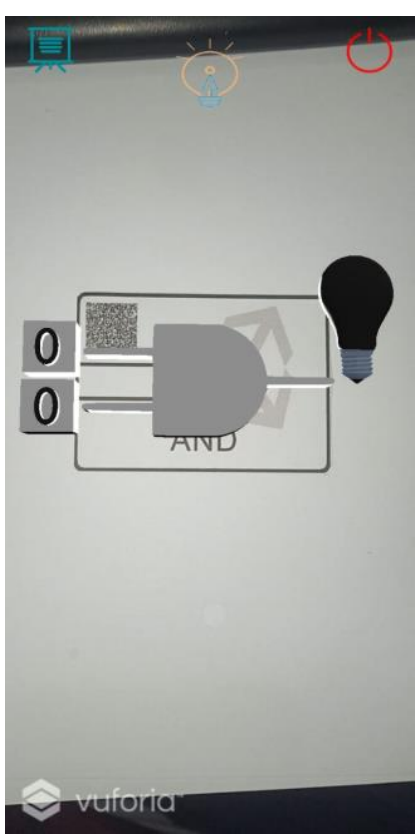

a)

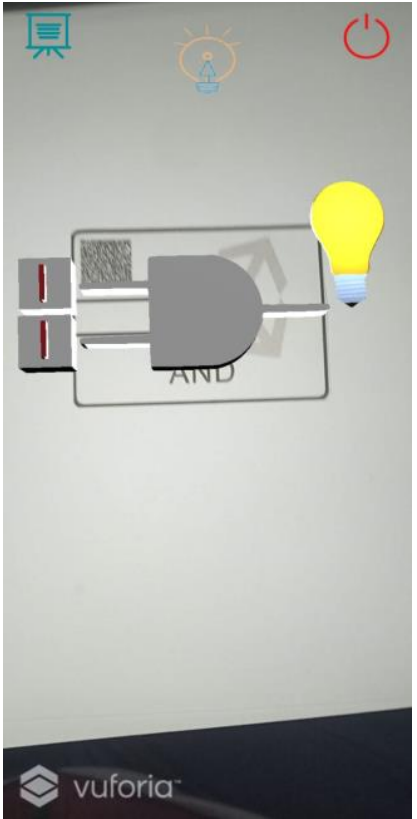

b)

Gambar 7. a) Saat marker sudah terdeteksi; b) Saat tombol ditekan

\section{Halaman Tentang}

Pada halaman tentang, berisi penjelasan aplikasi Augmented Reality pembelajaran gerbang logika. Serta tombol kembali. Jika tombol kembali ditekan maka akan langsung kembali ke menu utama. Halaman tentang seperti pada Gambar 8

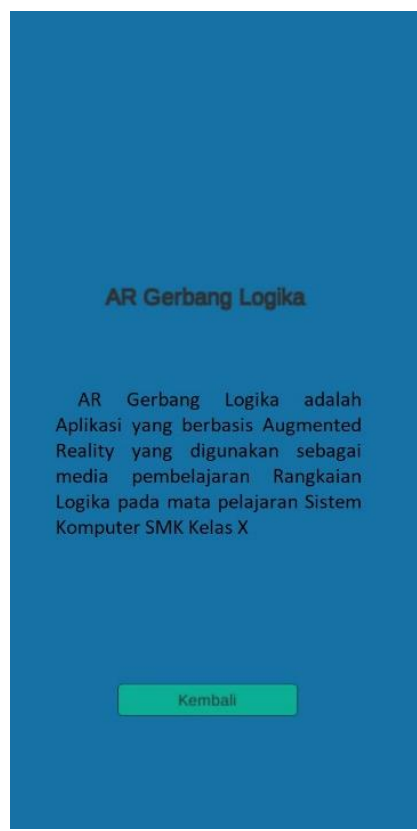

Gambar 8. a) Tampilan Halaman Tentang

\subsection{Hasil Pengujian}

Siswa pada kelompok kelas eksperimen melakukan pembelajaran gerbang logika menggunakan aplikasi Augmented Reality sebelum melakukan Post Test agar siswa dapat memahami bentuk gerbang logika 1 input dan bentuk-bentuk gerbang logika 2 input beserta interaksi input dan outputnya seperti ditunjukkan pada Gambar 9. 


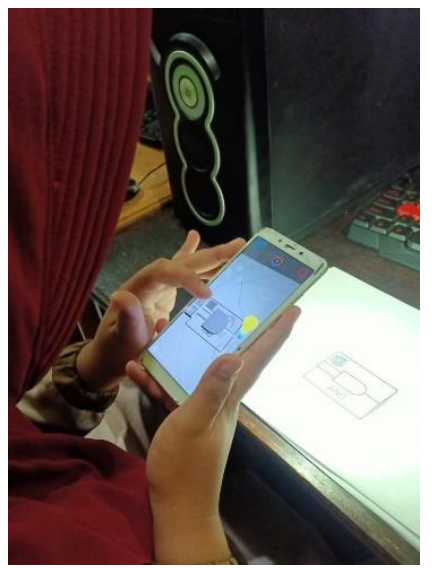

Gambar 9. Siswa kelompok eksperimen menjalankan aplikasi AR pembelajaran gerbang logika

Pertama yang dilakukan dalam pengujian adalah memberikan soal Pre Test kepada kedua kelompok yaitu kelompok kontrol dan kelompok eksperimen mengenai soal-soal gerbang logika. Soal Pre Test tersebut dengan jumlah soal yang sama dengan waktu yang sama. Selanjutnya, kelompok kontrol diberikan pembelajaran gerbang logika secara manual yaitu menggunakan buku ajar Sistem Komputer SMK kelas X dan menggunakan papan tulis sebagai percobaan, untuk kelompok eksperimen sistem pembelajaran gerbang logika menggunakan aplikasi Augmented Reality dan selanjutnya kedua kelompok tersebut diberikan ujian Post Test. Total nilai Pre Test dibandingkan dengan total nilai Post Test kemudian dihitung presentase kenaikan nilai dari Pre Test dan nilai dari Post Test. Berikut adalah grafik presentase kenaikan nilai dan grafik nilai rata-rata Pre Test dan post Test.

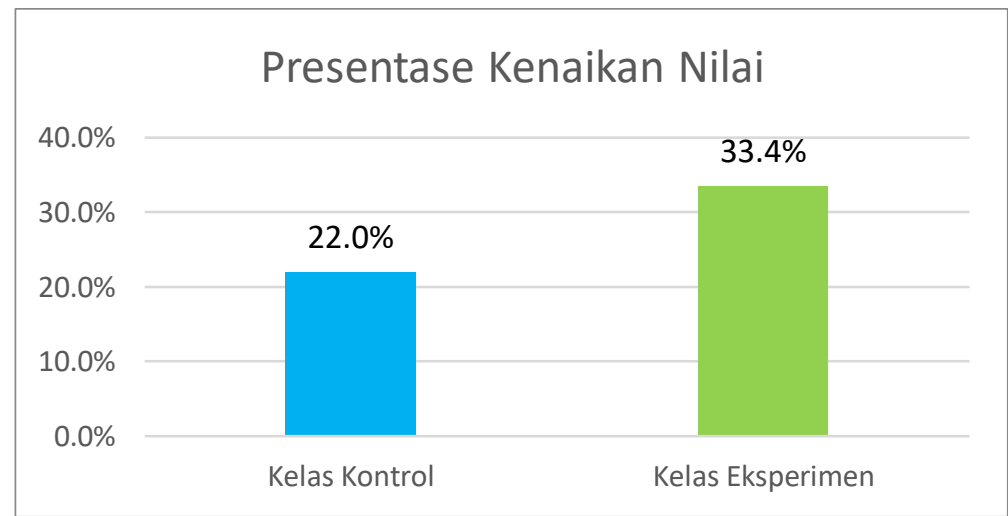

Gambar 10. Grafik presentase kenaikan nilai

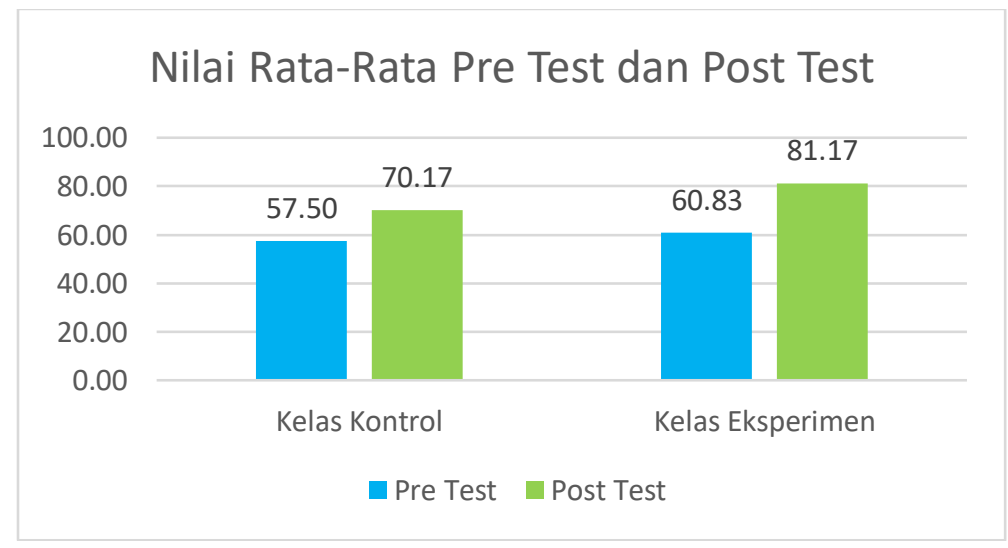

Gambar 11. Grafik nilai rata-rata Pre Test dan Post Test

\subsection{Analisis Hasil Pengujian}

Berdasarkan hasil pengujian Pre Test dan Post Test, untuk kelompok siswa yang sistem pembelajarannya secara manual yaitu menggunakan Buku Sistem Komputer SMK Kelas X dan papan tulis sebagai media pembelajarannya diperoleh nilai rata-rata 57,50 untuk Pre Test dan nilai rata-rata 70,17 untuk nilai Post Test, Sedangkan untuk kelompok siswa yang sistem pembelajarannya menggunakan aplikasi Augmented Reality diperoleh nilai rata-rata 
60,83 untuk Pre Test dan nilai rata-rata 81,17 untuk nilai Post Test. Untuk presentase kenaikan nilai dari Pre Test dan Post Test, untuk kelompok kelas kontrol mendapatkan nilai kenaikan sebesar $22 \%$, sedangkan untuk kelompok kelas eksperimen mendapatkan nilai kenaikan sebesar 33,4\%. Perbedaan presentase kenaikan nilai ini dipengaruhi oleh media belajar dari masing-masing kelompok kelas. Dimana saat pengujian dilakukan, kelompok eksperimen terlihat lebih tertarik dan lebih semangat dalam belajar gerbang logika. Sedangkan kelompok kontrol terlihat lebih cepat bosan saat belajar dan tidak fokus.

\section{KESIMPULAN}

Berdasarkan hasil penelitian dan pengujian aplikasi, dapat diambil kesimpulan bahwasannya Aplikasi Augmented Reality Untuk Pembelajaran Gerbang Logika pada mata pelajaran Sistem Komputer SMK kelas X ini telah berhasil dibuat, diimplementasikan dan digunakan dalam ujicoba kepada dua kelas yaitu kelas kontrol dan kelas eksperimen. Dari hasil pengujian Pre Test dan Post Test yang telah dilakukan, untuk kelas kontrol memiliki presentase kenaikan nilai sebesar 22,0\%, sedangkan untuk kelas eksperimen memiliki presentase kenaikan nilai sebesar 33,4\% yang berarti kelompok kelas eksperimen (kelas yang sistem pembelajarannya menggunakan aplikasi Augmented Reality gerbang logika) memiliki presentase kenaikan nilai yang lebih tinggi dari kelompok kelas kontrol yang sistem pembelajarannya tidak menggunakan Augmented Reality gerbang logika. Dengan demikian, dapat disimpulkan bahwa aplikasi dengan teknologi Augmented Reality ini dapat membantu dalam proses pembelajaran Gerbang Logika pada mata pelajaran Sistem Komputer SMK kelas X. Aplikasi ini perlu dikembangkan lagi dengan penambahan Quiz pada aplikasi sebagai Latihan soal bagi siswa dan perlu dilakukan pengembangan aplikasi pada fitur tampilan agar lebih responsif dengan menyesuaikan pada versi android yang terbaru.

\section{REFERENCES}

[1] R. Azuma, M. Billinghurst, and G. Klinker, "Special section on mobile augmented reality," Comput. Graph., vol. 35, no. 4, pp. vii-viii, 2011, doi: 10.1016/j.cag.2011.05.002.

[2] F. Ozdamli and D. Karagozlu, "Preschool teachers' opinions on the use of augmented reality application in preschool science education," Croat. J. Educ., vol. 20, no. 1, pp. 43-74, 2018, doi: 10.15516/cje.v20i1.2626.

[3] Y. Y. Yalinda and Noviana, Sistem Komputer C1 (Dasar Bidang Keahlian Teknologi Informasi dan Komunikasi SMK/MAK), Seri HOTS. Surakarta: CV Mediatama Anggota IKAPI No. 023/JTE/00, 2018.

[4] R. Hutahaean, R. R. Isnanto, and K. T. Martono, "Perancangan Aplikasi Multimedia Untuk Pembelajaran Gerbang Logika Menggunakan Augmented Reality,” J. Teknol. dan Sist. Komput., vol. 3, no. 1, pp. 125-131, 2016, doi: 10.14710/JTSISKOM.3.1.2015.125-131.

[5] H. Setiahadi, E. Setyati, and E. I. Setiawan, "Pembelajaran Ikatan Molekul Dalam Pelajaran Kimia Menggunakan Augmented Reality,” vol. 1, no. 2, pp. 80-86, 2017.

[6] R. Mauludin, A. S. Sukamto, and H. Muhardi, "Penerapan Augmented Reality Sebagai Media Pembelajaran Sistem Pencernaan pada Manusia dalam Mata Pelajaran Biologi," J. Edukasi dan Penelit. Inform., vol. 3, no. 2, p. 117, 2017, doi: $10.26418 /$ jp.v3i2.22676.

[7] A. Pramono and M. D. Setiawan, "Pemanfaatan Augmented Reality Sebagai Media Pembelajaran Pengenalan BuahBuahan," INTENSIF J. Ilm. Penelit. dan Penerapan Teknol. Sist. Inf., vol. 3, no. 1, p. 54, 2019, doi: 10.29407/intensif.v3i1.12573.

[8] R. S. Andre Kurniawan Pamoedji, Maryuni, Mudah Membuat Game Augmented Reality (AR) dan Virtual Reality (VR) dengan Unity. Jakarta: PT. Elex Media Computindo, 2017.

[9] J. White, D. C. Schmidt, and M. Golparvar-Fard, "Applications of Augmented Reality," Pro Android Augmented Reality, vol. 102, no. 2. pp. 1-12, 2012, doi: 10.1007/978-1-4302-3946-8_1.

[10] P. W. Aditama, I. N. W. Adnyana, and K. A. Ariningsih, “Augmented Reality dalam Multimedia Pembelajaran,” Pros. Semin. Nas. Desain dan Arsit., vol. 2, no. July, pp. 176-182, 2019.

[11] M. A. B. Rini Agustina, "Pemanfaatan Augmented Reality (Ar) Sebagai Media Pembelajaran Interaktif Pengenalan Candi Â Candi Di Malang Raya Berbasis Mobile Android,” Bimasakti, vol. 1, no. 5, pp. 1-6, 2017.

[12] I. Bagus and M. Mahendra, "Implementasi Augmented Reality ( Ar ) Menggunakan Unity 3D Dan Vuporia Sdk," J. Ilm. ILMU Komput. Univ. Udayana, vol. 9, no. 1, pp. 1-5, 2016.

[13] A. C. Manuputty, "Perancangan Augmented Realty Media Markerless Point Of Interest dalam Memberikan Informasi Gedung Berbasis Android (Studi Kasus : Universitas Kristen Satya Wacana,” J. Inform., vol. 11, no. 2, pp. 31-39, 2017, doi: 10.26555/jifo.v11i2.a6236. 